\title{
PREVENTION OF DENTAL CARIES WITH FLUORIDES IN HUNGARY
}

\author{
Melinda MADLÉNA, Lídia LIPTÁK \\ Semmelweis University, Department \\ of Paedodontics and Orthodontics
}

Corresponding author:

Melinda Madléna

1088 Budapest,

Szentkirályi str. 47

Hungary

madlena.melinda@dent.semmelweis-univ.hu

Tel./Fax.: + 3613187187

Received: April 30, 2014

Accepted: June 23, 2014

Copyright (C) 2014 by University Clinical Centre Tuzla. E-mail for permission to publish: paediatricstoday@ukctuzla.ba

\begin{abstract}
Although there has been great improvements of oral health in the world the problem is living especially in Central and Eastern European countries. Hungary could be found on the borderline between Central and Eastern Europe representing a gate to the Western European Countries. Large variety uses of fluoride and other methods have been recognized for preventing dental diseases. From among regarding the systemic fluoride prevention a salt fluoridation programme was introduced between 1966 and 1983 in Szeged and surroundings organized by Károly Tóth. An other systemic fluoride programme was introduced by Jolán Bánóczy in Fót, nearby Budapest between 1978 and 1990. Both programmes resulted in better oral health in the involved populations. A topical fluoride Elmex programme was performed by Judit Szőke in 1980 which showed good results with significant improvements of oral hygiene and caries increment in the test group. During the past period the only National Oral Health Programme was organized between 1986 and 1995 included administration of fluoride tablets in most kindergarten and primary schools, use of fuoride toothpaste, oral hygiene instruction and dietary counseling. Although there were a lot of problems during that period this programme resulted in mostly positive outcomes like trend of caries became decreasing and prevalence of gingivitis reduced. After finishing this programme preventive activity has been reduced considerably, the current situations of oral health and related factors are unfavourable. Conclusion - It would be necessary to organize and finance a new governmental programmes including complex preventive oral care to improve oral health in Hungary.
\end{abstract}

Key words: Systemic fluoride prevention - Local fluoride prevention National Dental Health Programme • Dental prevention • Hungarian dental preventive programmes.

\section{Introduction}

Despite the great improvements in oral health of different populations in the world, the problem of dental diseases still exists. According to the WHO Report (2003) dental caries remains a major public health problem in most industrialized countries, affecting $60-90 \%$ of schoolchildren and the vast majority of adults (1). Among the European countries, the problem is especially severe in the eastern part of Europe. In Central and Eastern Europe the oral health care systems are in transition due to economic and political changes (2). Hungary is on the borderline between Central and Eastern Europe representing a gateway to the Western European countries. Its population is about 10 million. 
The aim of the study is to provide a historical review of Hungarian preventive programs organized in the past and the current situation regarding preventive dental care in Hungary.

\section{Fluoride and oral health}

The importance of fluoride (F) as a caries preventive agent was firstly observed in the 1930 s in relation to its concentration in natural water. From that beginning, a large variety of possibilities have been suggested for the systemic and topical administration of F. All of them seem to be effective in reducing dental caries in those countries where different methods are being widely used. Concerning the systemic method, fluoridation of drinking water, salt or milk is cost effective, and has an important role in caries prevention $(3,4)$. It has been shown in the literature that water fluoridation reduces the prevalence of dental caries by $15 \%$. At the same time it has also been shown that at certain concentrations of $\mathrm{F}$, water fluoridation is associated with an increased risk of aesthetically unfavourable dental fluorosis $(5,6)$. However, further analysis has suggested that the risk might be substantially greater in naturally fluoridated areas and less in artificially fluoridated areas. Table 1 shows the possible health effects, depending on the concentration of $\mathrm{F}$ in natural drinking water (7).

\begin{tabular}{ll}
$\begin{array}{l}\text { Table } 1 \text { Possible health effects of fluoride } \\
\text { depending on the concentration in drinking } \\
\text { water (7) }\end{array}$ \\
\hline $\begin{array}{l}\text { Concentration of } \\
\text { fluoride }(\mathrm{mg} / \mathrm{l})\end{array}$ & Possible health effects \\
\hline Less than 0.5 & $\begin{array}{l}\text { Dental cavities may occur } \\
\text { No adverse health effects, cavities } \\
\text { decrease }\end{array}$ \\
Greater than 1.5 & $\begin{array}{l}\text { Mottling of teeth and dental } \\
\text { fluorosis may occur } \\
\text { Association with skeletal fluorosis at } \\
\text { higher concentrations }\end{array}$ \\
\hline
\end{tabular}

\section{Fluoride in drinking water}

Although water fluoridation is the most widely used public health measure for caries prevention, less than $10 \%$ of the world's population is able to have access to this possibility as it is not feasible in many areas because of the nature of water supplies $(5,6)$. In Hungary, $98.8 \%$ of the population live in such areas of the country, where the concentration of natural $\mathrm{F}$ is less than $0.6 \mathrm{mg} / \mathrm{l}$ (8). Despite this situation, water fluoridation has not been introduced in Hungary. In the 1980s nearly all settlements with piped water supplies had one or more of their own water sources a huge number of fluoridated plants would be needed, with very high costs. Further problems would involve organizing the maintenance and supervision of the system, and the fact that this programme could not provide any benefit for those inhabitants who lived without central water supplies (8).

\section{Systemic administration of fluoride in Hungary}

\section{Fluoride in domestic salt}

Based on experiences regarding consumption of foods prepared with $\mathrm{F}$ containing salt, it was found that the highest levels of $\mathrm{F}$ in blood were less than when using water containing F. This means that the safety of fluoridated salt is at least as much as that of fluoridated water. The examinations showed that $\mathrm{F}$ levels in urine was the same using fluoridated salt, with $250-300 \mathrm{mg} \mathrm{F} / \mathrm{kg}$, as in the case of consumption of water with $1 \mathrm{mg} / \mathrm{l} \mathrm{F}$ (9).

Specific indications for salt fluoridation were the previously mentioned situation with water fluoridation and the fact that the consumption of sugar increased from $38,000 \mathrm{t}$ to $468,000 \mathrm{t}$ and candy production increased from $11,000 \mathrm{t}$ to $31,000 \mathrm{t} /$ year between 1960 and 1980 in Hungary. This high risk situation was seen in high caries prevalence in low fluoridated areas, where an average of 
10 DMFT was found in 14 year olds. This value was about three times higher than the published level of caries prevalence in most industrialized countries (8).

Salt fluoridation has more comparative advantages. It is relatively low in cost, safety, not compulsory, and does not require individual action or active contributions to ensure its beneficial effect. Between 1966 and 1983 salt fluoridation was performed, although only in the southern part of Hungary, in Szeged and surroundings (where there is a low fluoride level in drinking water) by Professor Károly Tóth (6-8). The programme was organised in five experimental and four control villages with nearly 30,000 inhabitants in total. Domestic salt was introduced with 250 $\mathrm{mg} \mathrm{F} / \mathrm{kg}$ in 1966, then with $300 \mathrm{mg} \mathrm{F} / \mathrm{kg}$ in 1968 and $350 \mathrm{mg} \mathrm{F} / \mathrm{kg}$ in 1972, not only for individual use but it was used in restaurants, for school meals etc. Only these types of salts could be bought in the experimental places during the relevant periods $(8,9)$. Using different concentrations of fluoride the authors thought that they would be able to mimic the situation created by consumption of drinking water with different water-borne $\mathrm{F}$ content. The effects of this salt fluoridation programme on changes in $\mathrm{dmft} / \mathrm{DMFT}(\mathrm{d} /$ Decayed, m/Missing, f/Filled t/Teeth) are published by Professor Tóth (8).

Caries prevalence was significantly reduced in the experimental groups using fluoridated salt compared to the controls in all age groups. The level of caries was significantly reduced both in primary and permanent dentitions $(\mathrm{p}<0.05)(8)$.

In 1983, after the salt fluoridation programme ended, an international panel discussion was organized at the University Medical School in Szeged, Hungary to consider possibilities for caries prevention, especially focusing on salt fluoridation as a possible public health measure in Hungary (9). This meeting included three main topics: 1 . den- tal screening of children in those two villages (experimental/test and control groups) where the salt fluoridation program had been conducted by Professor Tóth; 2. the scientific part with the results of the salt fluoridation programme and 3. discussion and conclusions from the salt fluoridation programme.

\section{Conclusions of the salt fluoridation programme and the panel discussion}

Domestic salt fluoridation was found to be a suitable automatic method for caries prevention. Regular, continuous consumption of domestic salt containing $250 \mathrm{mg}$ F per kg results in significant reduction of caries, both in deciduous and permanent teeth. The degree of caries reduction using domestic salt containing less than $250 \mathrm{mg}$ F/ $\mathrm{kg}$ (200 mg F/ $\mathrm{kg}$ ) does not result in a similar effect, the reduction is less. Use of domestic salt containing $350 \mathrm{mg} \mathrm{F} / \mathrm{kg}$ showed the best results (9).

There were no more side effects or significantly mottled enamel in any of the three experimental groups using salt containing 200, 250 or $350 \mathrm{mg} \mathrm{F} / \mathrm{kg}$ in comparison with in control groups without fluoridated salt $(9,10)$. Salt fluoridation is an effective method but its beneficial effects may only be experienced in case of permanent and continuous ingestion.

In Hungary, as the latest intervention for systemic fluoride prevention, the general introduction of fluoridated salt containing 250 $\mathrm{mg} \mathrm{F} / \mathrm{kg}$ was performed in 2000 for individual use only. It means only that anybody can buy this type of domestic salt (the price of which is much higher than the price of "normal" salt without fluoride) and use it individually, but there is no information about the effect of usage and side effects.

\section{Fluoride in milk}

Regarding this method, the first investigations were performed in the early 1950s. After 
these studies the Borrow Dental Milk Foundation was established for further research into this favourable method. A large number of publications show the bioavailability and effectiveness of fluoride in this form. There are many preventive programmes sponsored by the Borrow Foundation which provide good possibilities for children. It is suggested that the programmes are run for at least 200 days in a year, especially in those children who consume drinking water with low natural fluoride and show a high prevalence of caries (11-13).

In Hungary a milk fluoridation programme was organised, as part of the international milk fluoridation programme, in a closed community of children in Fót near Budapest, by Jolán Bánóczy (1978-1990). The majority of children who lived there had been abandoned by their parents. This closed community, with its own internal school, provided the ideal circumstances for the milk fluoridation programme. The $\mathrm{F}$ level of drinking water was low, $0.03 \mathrm{ppm}$, the milk and milk products consumed contained $0.02 \mathrm{ppm} \mathrm{F}$.

The programme, which was sponsored by the Borrow Milk Foundation, first involved kindergarten children aged 2-5 years at the outset, and one year later it was extended to primary school children aged 6-12 years. Each participant consumed $200 \mathrm{ml}$ milk or cocoa milk for breakfast, containing $0.4 \mathrm{mg}$ $\mathrm{F}$ for kindergarten children and $0.75 \mathrm{mg} \mathrm{F}$ for primary school children, every day for a period of 180-200 days per year. Trained personnel added the F doses (sodium fluoride solutions prepared by the Pharmacy of Semmelweis University in closed glass bottles) to the milk and stirred thoroughly for at least 10 minutes. The drinks were consumed within 30 minutes (11).

Before starting the programme, urinary fluoride excretion was determined and this was followed by weekly and later monthly measurements from randomly selected pupils. Dental examinations were also performed by four calibrated dentists before starting the programme and then annually. The data were compared to a control group who lived in the same circumstances and did not consume fluoridated milk (11).

The results showed that after five years considerable caries reductions were observed in the test groups, both in primary and permanent dentition (11). Compared to the control groups these reductions were $54 \%$ in DMFT values and $53 \%$ in DMFS values in the test groups of 7-10 year olds. Between the test and control groups a statistically significant difference could be found in $\mathrm{dmft}$ and $\mathrm{dmfs}$ values in 7-10 year old children after four and five years (Table 2) $(11,12)$.

After ten years there were no caries free children in the control groups while in the test groups about $20 \%$ of 12 and 14 year-old pupils were caries free (Fig. 1) (11).

Regarding the 10 year results, only in the group of 12-14 year olds were there significant differences between test and control DMFT and DMFS mean values. The best

Table 2 Comparison of dmft and dmfs mean values in the test (T) and control (C) groups after 4 (T1/C1) and 5 (T2/C2) years of milk fluoridation $(11,12)$

\begin{tabular}{|c|c|c|c|c|c|c|c|}
\hline \multirow{2}{*}{ Group } & \multicolumn{2}{|l|}{ Age (y) } & \multirow{2}{*}{$\mathrm{n}$} & \multirow{2}{*}{$\mathrm{dmft}$} & \multirow{2}{*}{$\begin{array}{l}\text { Statistical } \\
\text { significance }\end{array}$} & \multirow{2}{*}{$\mathrm{dmfs}$} & \multirow{2}{*}{$\begin{array}{l}\text { Statistical } \\
\text { significance }\end{array}$} \\
\hline & At examination & At start of milk F & & & & & \\
\hline T1 & $9-12$ & $5-8$ & 83 & 1.42 & \multirow{2}{*}{ N.S. } & 2.67 & \multirow{2}{*}{ N.S. } \\
\hline $\mathrm{C} 1$ & $9-12$ & - & 64 & 1.69 & & 2.77 & \\
\hline $\mathrm{T} 2$ & $7-10$ & $2-5$ & 69 & 2.4 & \multirow{2}{*}{$\mathrm{p}<0.001$} & 3.79 & \multirow{2}{*}{$\mathrm{p}<0.001$} \\
\hline $\mathrm{C} 2$ & $7-10$ & - & 81 & 4.01 & & 6.40 & \\
\hline
\end{tabular}

F=Fluoridation. 


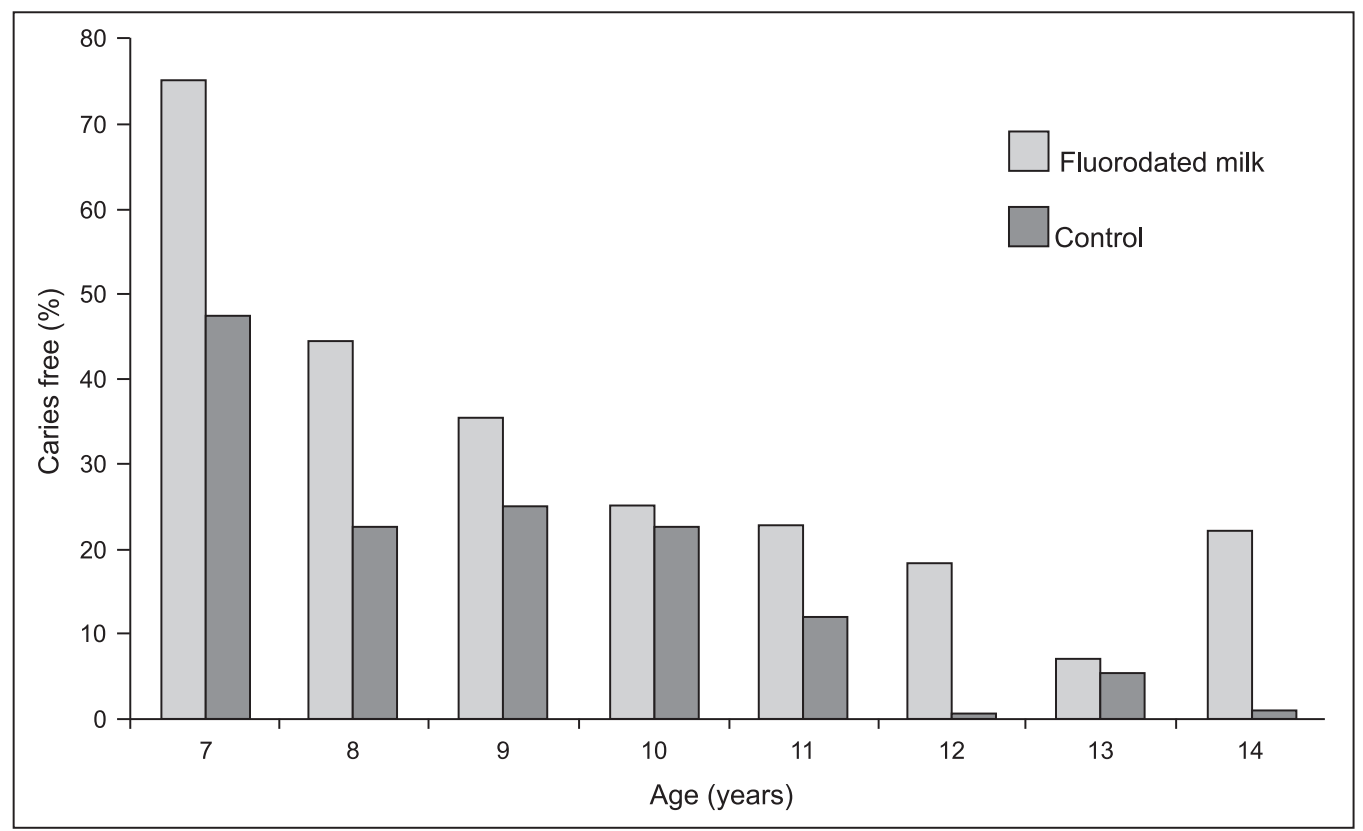

Fig. 1 Percentage distribution and age of caries free children after 10 years of fluoridated milk consumption (11).

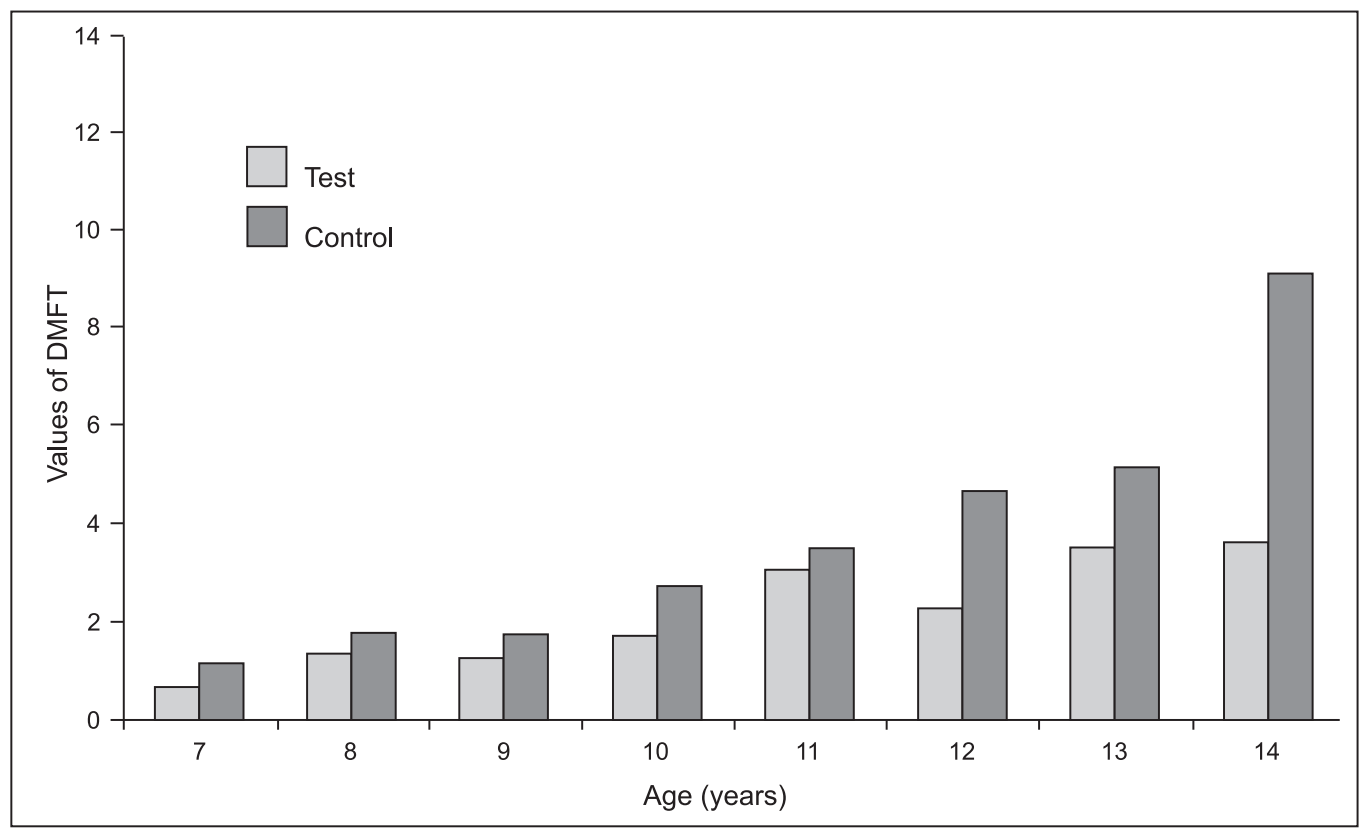

Fig. 2 DMFT mean values in the test and control groups after 10 years of fluoridated milk consumption (11).

results were found in those groups who consumed fluoridated milk from 2 to 3 years of age and in those pupils who consumed fluoridated milk for the longest time. The DMFT (and DMFS) mean values of 14 year olds were nearly three times lower than in controls (Fig. 2) (11).

There was a statistically significant reduction between the test and control groups after ten years. Upon calculating the overall mean 
caries increment between the test and control groups, 37\% DMFT and 40\% DMFS reductions were observed. The results of the Hungarian studies indicate that both salt and milk fluoridation, on the basis of experiences in different communities, are effective methods in reducing dental caries.

\section{Topical administration of fluoride in Hungary}

Regarding local fluoride prevention, an Elmex toothpaste and gel programme was introduced by Judit Szőke in 1980. GABA was the first foreign firm in Hungary, with donated products. Elmex products contain amine fluoride. Besides its fluoride effect, it has antibacterial properties: it spreads over all surfaces in the oral cavity especially quickly (as a result of its tenside character), shows longer clearance in the oral cavity and dental plaque, and has a pronounced activity against plaque. It is strongly glycolytic (for 3-6 hours) and therefore develops a highly bacteriostatic and bactericide effect (14).

The results of the Elmex program were published in 1989. This study was performed in six year olds for three years. In the control group the participants used amine fluoride containing (Elmex) toothpaste twice a day, while in the test group, besides using Elmex toothpaste twice a day, Elmex gel was applied once a week. This application resulted in significant improvement of oral hygiene in the test group and a significant difference in caries increment between the two groups $(\mathrm{p}<0.001)$, which is shown in Fig. 3 (15).

After that, apart from the National Health Program (see below) which also included Elmex gel application once a week, there have only been some local programmes in different populations showing the beneficial effects of oral hygienic products containing fluoride (mostly amine fluoride) on oral health (16).

Among these studies, one of the most important programmes was a long term school based preventive program. It was scheduled for two years with the combined use of amine fluoride toothpaste and gel in 14-16 year old adolescents. On the basis of a previous assessment of their oral hygiene and dental status, they were considered as a high risk group (17). The results showed that combined use of products containing fluoride (toothpaste twice a day, and gel once a week) resulted in better caries reduction, improvement of oral

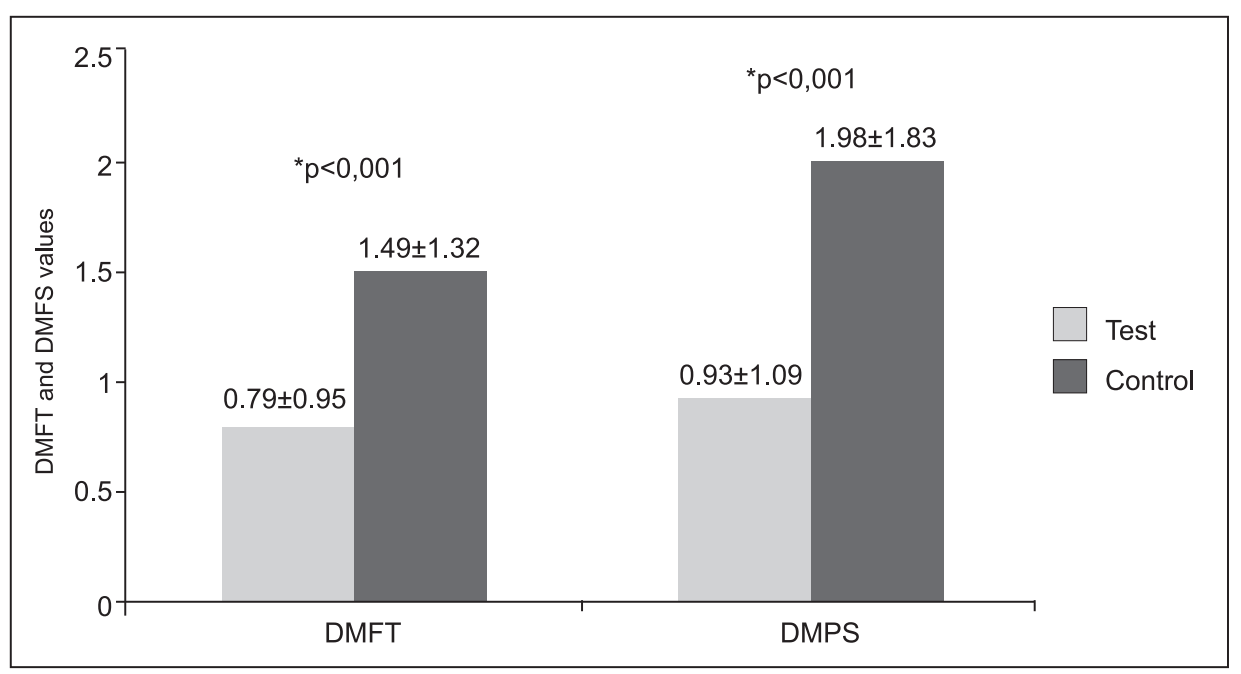

Fig. 3 Caries increment in DMFT and DMFS values (mean \pm S.D.) (excluding incipient caries after three years treatment with Amine fuoride gel) (15). 
hygiene and a remineralization effect than use of toothpaste alone $(17,18)$. Regarding the results, significant differences could be found between the groups using toothpaste and gel together compared with the groups using toothpaste only $(\mathrm{p}<0.05)$.

\section{The national oral health programme - systemic and topical administration of fluoride in Hungary}

By the 1980s the dental public health situation was very unfavourable. Regarding the level of fluoride is remains unchanged: $98.8 \%$ of the population consume water containing less than $0.6 \mathrm{mg} \mathrm{F} / \mathrm{l}$, and $90.4 \%$ consume less than $0.25 \mathrm{mg} \mathrm{F} / \mathrm{L}$. There is no water or any other systemic fluoridation programme, except the administration of fluoride tablets in nursery and kindergarten in Budapest (only) since 1970 (19). There was only 30\% of dentifrice containing fluoride available and there was no other products containing fluoride on the market. The use of toothbrush was 0.5 piece / person/year and that of toothpaste 1.5 tubes / person/year. At the same time, unhealthy nutrition was typical with high sugar consumption (40 kg/person/year). There were no preventive personnel or programmes $(20,21)$.

This unfavourable situation was recognized by the government. Between 1986 and 1995 the National Oral Health Programme was introduced, including administration of fluoride tablets („Dentocar”) in most kinder- gartens and primary schools. The National Oral Health Program also comprised topical gel application in schools, use of fluoride toothpaste, oral hygiene instruction and dietary counselling $(22,23)$.

At the beginning of this national programme, Preventive Dental Committees were established in the capital and all (19) counties of the country to organize and monitor the programme. The committees included the persons responsible for the health and education of children. Regarding systemic prevention, free administration of tablets containing fluoride („Dentocar” or „Dentocar forte") was introduced to the communities of children first for 0-6 year olds and then for children up to 10 years of age. The fluoride supplementation was performed with the informed consent of parents. F tablets, containing $0.23 \mathrm{mg}$ or $1 \mathrm{mg}$ fluoride, were given by the personnel of the institutes or the parents at home, on the basis of prescriptions issued by paediatric doctors or paediatric dentists. The system of administration of F containing tablets, depending on the age and $\mathrm{F}$ level of drinking water, is shown in Table 3.

Regarding local prevention, oral hygienic products, toothpaste, mouth rinse containing fluoride were offered for use at home and gel containing fluoride was applied professionally in primary schools, once a week. Application of this Elmex gel could be performed in school classes with the participation of teachers.

Table 3 Recommendations for fluoride tablets (tbls.; "Dentocar") program

\begin{tabular}{llll}
\hline \multirow{2}{*}{ Age (years) } & \multicolumn{3}{l}{ Offered daily dose depending on the $\mathrm{F}$ content of drinking water } \\
\cline { 2 - 4 } & $0-0.25 \mathrm{mg} / \mathrm{l}$ & $0.25-0.5 \mathrm{mg} / \mathrm{l}$ & $0.5-0.75 \mathrm{mg} / \mathrm{l}$ \\
\hline 0-2 year olds & 1 tbls. Dentocar $(\mathrm{F}=0.23 \mathrm{mg})$ & - & - \\
3-4 year olds & 2 tbls. Dentocar $(\mathrm{F}=0.46 \mathrm{mg})$ & 1 tbls. Dentocar $(\mathrm{F}=0.23 \mathrm{mg})$ & - \\
$5-6$ year olds & 3 tbls. Dentocar $(\mathrm{F}=0.69 \mathrm{mg})$ & 2 tbls. Dentocar $(\mathrm{F}=0.46 \mathrm{mg})$ & 1 tbls. Dentocar $(\mathrm{F}=0.23 \mathrm{mg})$ \\
7 or more year olds & 4 tbls. Dentocar $(\mathrm{F}=0.92 \mathrm{mg})$ & 3 tbls. Dentocar $(\mathrm{F}=0.69 \mathrm{mg})$ & 2 tbls. Dentocar $(\mathrm{F}=0.46 \mathrm{mg})$ \\
& or 1 tbls. Dentocar forte $(\mathrm{F}=1 \mathrm{mg})$ & & \\
\hline
\end{tabular}


Regarding oral hygienic instruction and motivation, classroom based exercises in tooth brushing and interactive health education were conducted 2-4 times/year according to the age of the children. The school dental system offered many activities in these education programmes.

The National Health Programme has had a large number of positive outcomes and results, first of all the introduction of tablets containing F, now most available toothpastes contain fluoride, a large number of different types of oral hygienic products are available, use of toothpaste and toothbrushes has improved (from 1.5 to 3 tubes of toothpaste and from 0.5 to 1 toothbrush). Many books and other publications related to dental prevention are available. There have also been epidemiological results: the trend of caries is decreasing (from high to moderate) and the prevalence of gingivitis also decreased in 12 year old children between 1985 and 1991 (Fig. 4, Table 4) (24-26).

Beside the advantages of the National Health Programme there were many problems during that period and there were/are some limitations to the results. One of the most important difficulties was an anti-fluoride campaign run by some persons in high positions in dental education. They published widely that fluoride is a rat poison which has negative effects on the health of children. In

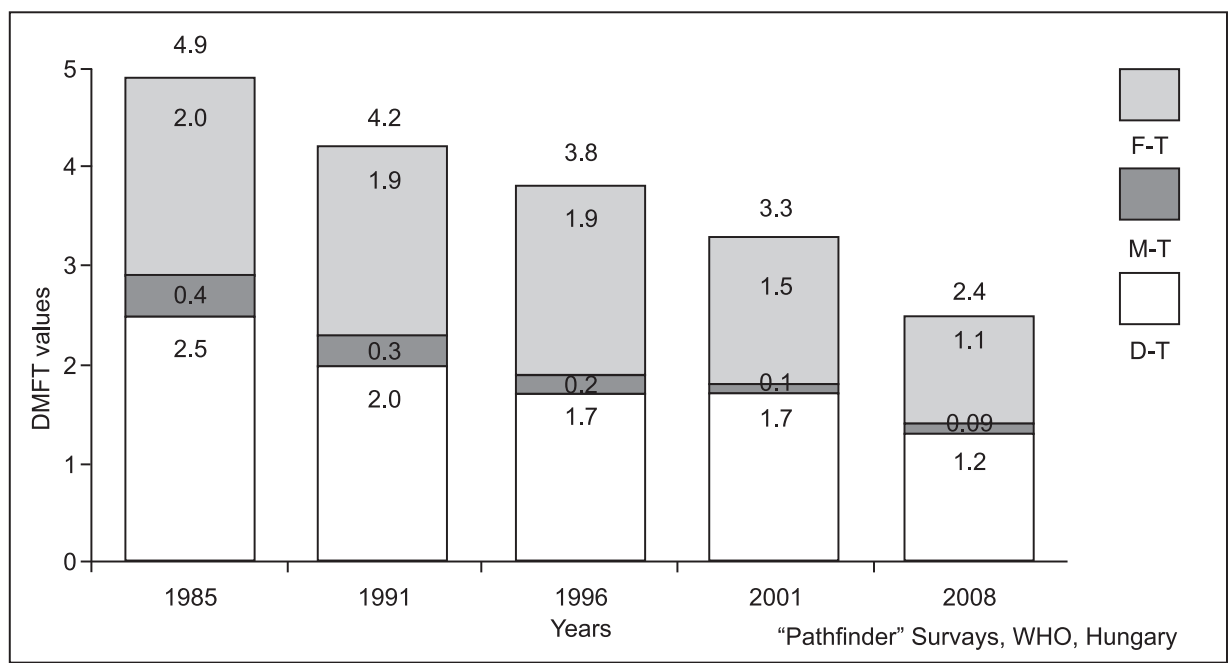

Fig. 4 The mean caries experience (DMFT) of 12 year-old children between 1985 and 2008 (24-26).

Table 4 Changes in values of CPI between 1985 and 1996 in 12 year old children $(25,26)$

\begin{tabular}{llll}
\hline \multirow{2}{*}{ CPI } & \multicolumn{2}{l}{ Values of CPI } & In 1996 \\
\cline { 2 - 4 } & In 1985 & In 1991 & 28 \\
\hline 0 (Healthy) & 26.2 & 39.1 & 39.7 \\
1 (Bleeding) & 38.5 & 30.8 & 32.3 \\
2 (Bleeding + calculus) & 30.9 & 30.1 & - \\
3 (Pocket depth 4-5 mm) & 4.1 & - & - \\
4 (Pocket depth $+\mathrm{mm}$ ) & 0.1 & - & - \\
\hline
\end{tabular}

$\mathrm{CPI}=$ Community Periodontal Index. 


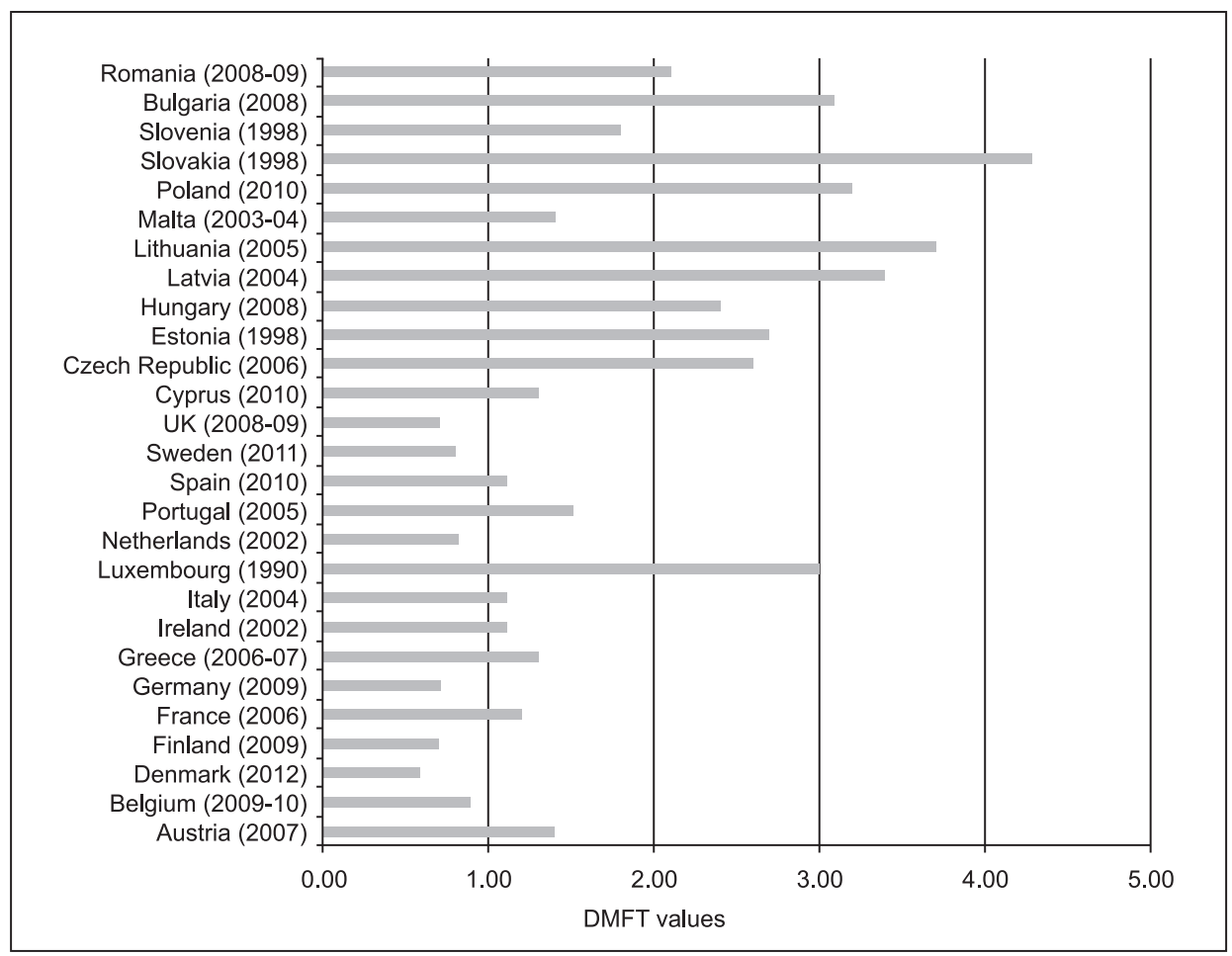

Fig. 5 DMFT scores for 12 year olds in EU countries (28).

spite of intensive nutritional education there was only limited improvement in nutritional habits, the yearly ingestion of sugar has not decreased (27), further unhealthy foods are available in the school buffets. There is a lack of personnel in preventive dental education and there was no really positive change in the preventive approach of dental personnel, which was (and is) related to the lack of proper financial resources. Besides these facts, a lack of appreciation regarding preventive activities was (and still is) also a problem. In these circumstances it is very hard to perform successful preventive activities and emphasize the importance and necessity of dental preventive care.

From the historical review, we see that the only nationwide programs are the national oral health programmes from 1986 until 1995, and domestic salt fluoridation since 2000. All the other projects mentioned were more like clinical studies, pilot projects or localized activities. All these programmes and studies showed significant effects on oral health.

After the end of the National Oral Health Programme since the mid-1990s most preventive care activities have come to a halt due to the transition of health care and privatization of oral health services. What is the epidemiological situation in Hungary now? Fig. 5 shows its ranking among EU countries (including Eastern European countries) based on the DMFT levels in 12 year olds (28). According to the latest data published this number is lower (2.4) in Hungary than in most other East European countries (2.6-4.3) in the EU (except for Romania and Slovenia) but we could not reach the WHO target in time (DMFT: max. 3), by 2000 (WHO).

We have to make a significant effort to reach the next WHO target DMFT value for 2020 (DMFT $\leq 1.5)$ (29). The trend in DMFT values in 12 year olds may be seen 
in Fig. 5, where it has been shown that unfortunately the highest values on the index represent decayed teeth ( $\mathrm{D}$ value) (24). The prevalence of gingivitis is nearly $40 \%$, the prevalence of calculus is $32.3 \%$ according to the latest data (1996) in this age group and these data are higher than the data from 1991 (Table 4) $(25,26)$. According to the latest data (2007) the annual consumption of sugar is high, nearly $46 \mathrm{~kg} /$ capita, and shows a considerable increase compared to the data from $2000(36.7 \mathrm{~kg} /$ capita $)$. Only a very slight fall is visible compared to the previous data from 2005 (46.4 kg/capita) (27). The current use of toothbrushes is 1.13 toothbrushes/person/ year and 3.44 tubes of toothpaste/person per year according to the latest available data (2010).

\section{Conclusion}

Despite the unfavourable situation there is currently no governmental or any other financial support for a public health programme including preventive oral care and to improve oral health in Hungary. The reorganization of school dental services, monitoring their activities, widespread education of the population regarding proper oral hygiene, healthy nutrition, the use of fluoride toothpaste and other fluoride methods would be of fundamental importance to improve the dental public health situation in Hungary.

Acknowledgement: The authors are very grateful to Dr. Judit Szokke for the information regarding the National Health Programme, making the figure on DMFT values of WHO pathfinger studies (Fig. 4) available for the authors.

Authors'contribution: Conception and design: MM; Aquisition, analysis and interpretation of data MM and LL; Drafting the article: MM an LL; Revising it critically for important intellectual content: MM and LL.

Conflict of interest: The authors declare that they have no conflict of interest.

\section{References}

1. World Health Organization [homepage on the internet]. The World Oral Health Report 2003 WHO, Geneva, Switzerland pp 3-13. [accessed 2014 Apr 15]. Available from: http:/www.who.int/ oral_health/publications/report03/en.

2. Petersen PE. Changing oral health profiles of children in Central and Eastern Europe. Challenges for the 21st century. [accessed 2014 Apr 15]. Available from: http:/www.who.int/oral_health/publications.

3. The World Oral Health Report 2003 WHO, Geneva, Switzerland pp 19-20. [accessed 2014 Apr 15]. Available from: http:/www.who.int/oral_health/ publications/ report03/en

4. Bánóczy J, Marthaler TM. History of fluoride prevention: successes and problems (literature review). Fogorv Szle. 2004;97(1):3-10.

5. McDonald MS, Whiting PF, Wilson PM, Sutton AJ, Chestnutt I, Cooper J, et al. Systematic review of water fluoridation. Brit Med J. 2000;321(7265):855-9.

6. Medical Research Council [homepage on the internet]. Water fluoridation and health. Working group report Sept 2002. [accessed 2014 Apr 15]. Available from: http://www.mrc.ac.uk/Utilities/ Documentrecord/index.

7. Guidelines for drinking Water Quality. Geneva: World health organization;1996.

8. Tóth K. Caries Prevention by Domestic Salt Fluoridation. Budapest: Akadémiai Publisher; 1984.

9. Tóth K. Salt fluoridation Conference [in Hungary]. Fogorv Szle.1985;78 (4):117-21.

10. Tóth K. Fluoridated domestic salt and its effect on dental caries over a 5-year period. Caries Res.1976;10(5):394-9.

11. Bánóczy J, Petersen PE, Rugg-Gunn AJ, editors. Milk fluoridation for prevention of dental caries. 2nd ed. Geneva: World Health Organization; 2009.

12. Bánóczy J, Rugg-Gunn A. Caries prevention through the fluoridation milk. Fogorv Szle. 2007;100(5):185-92.

13. Bánóczy J, Rugg-Gunn A, Woodward M. Milk fluoridation for prevention of dental caries. Acta Medica Academica. 2013;42(2):156-67.

14. Brecx M. Strategies and agentsin supragingival chemical plaque control. Periodontol 2000. 1997;15(1):100-8. 
15. Szőke J, Kozma M. Results of 3-year study of toothbrushing with amine fluoride gel. Oralprophylaxe. 1989;11(4):137-43.

16. Madléna M. Experiences with amine fluoride containing products in the management of dental hard tissue lesions focusing on Hungarian studies. Acta Medica Academica. 2013;42(2):189-97.

17. Madléna M. Nagy G, Gábris K, Márton S, Keszthelyi G, Bánóczy J. Effect of Amine Fluoride Toothpaste and Gel in High Risk Groups of Hungarian Adolescents: Results of a Longitudinal Study. Caries Res. 2002;36(2):142-6.

18. Márton S, Nagy G, Gábris K, Bánóczy J. Logistic regression analysis of oral health data in assessing the therapeutic value of amine fluoride containing products. Oral Health Dent Manag. 2008;7(4):26-9.

19. Csocsán Gy. Effect of Dentocar tablets [in Hungary]. Fogorv Szle. 1980;73(8):250-1.

20. Makra Cs, Hidasi Gy, Paphalmy Zs. Task of pedodontic care based on complex studies [in Hungary]. Fogorv Szle. 1984;77(5):129-34.

21. Hidasi Gy, Makra Cs, Paphalmy Zs. The aim of child dental health care based on complex investigation [in Hungary]. Fogorv Szle. 1984;77(7):203-8.

22. Orsós S. The prevention programme of Gödöllo” from the view point of dental service [in Hungary]. Fogorv Szle. 1986;79(2):46-7.
23. Öri I. About the caries prevention programme [in Hungary]. Fogorv Szle 1986;79(2):56-7.

24. WHO database [accessed 2014 Apr 15]. Available from: http:/ www.mah.se/CAPP/Country-OralHealth-Profiles/EURO/Hungary

25. Szőke J and Petersen PE Oral health of children - National situation based on the recent epidemiological surveys [in Hungary]. Fogorv Szle 1998; 91(10):305-14.

26. Márton K, Balázs P, Bánóczy J, Kivovics P. The dental aspects of public health in Hungary. Review article [in Hungary]. Fogorv Szle. 2009; 102(2): 53-62.

27. World Health Organization [homepage on the internet] [accessed $2014 \mathrm{Apr}$ 15]. Available from: http:/ www.mah.se/CAPP/Country-Oral-HealthProfiles/EURO/Hungary/Information-Relevantto-Oral-Health-and-care/Sugar Consumption

28. World Health Organization [homepage on the internet] [accessed 2014 Mar 25]. Available from: http:/ www.mah.se/CAPP/Country-Oral-HealthProfiles/EURO/Hungary/Oral Diseases

29. Hobdell M, Petersen PE, Clarkson J, Johnson N. Global goals for oral health 2020. Int Dent J. 2003;53(5):285-88. 